\title{
Cannabis farmers or criminals? Enforcement-first approaches fuel disparity and hinder regulation
}

\author{
Siskiyou County, and many other counties, chose not to recognize cannabis cultivation as \\ agriculture. This ethnographic study reveals the effects on parity in farmer rights and access \\ to resources.
}

by Michael Polson* and Margiana Petersen-Rockney*

" 1 is not agriculture in any way, shape or form," ficial in response to our questions about cannabis cultivation. Away from the green valleys of irrigated alfalfa and pasture, in the dry rocky hills, a new set of producers has gained public attention, who, the county agricultural official asserted, "are not farmers." According to Siskiyou's Planning Division, cannabis is a unique crop that "differs from ... traditional crops like strawberries or alfalfa in that cannabis remains classified by the federal government as a Schedule I drug" (Siskiyou County 2017a, 3). Despite cannabis now being a legal commodity in the state, in many counties, including Siskiyou County, cannabis cultivation has been disqualified as agriculture and substantively recriminalized.

* These authors contributed equally as co-first authors.

Online: https://doi.org/10.3733/ca.2019a0017

Many cannabis farms in Siskiyou County are located on mostly undeveloped subdivision lots, which are often sparsely vegetated, dry, hilly and small, making them highly visible from public roads, horseback, neighboring plots, helicopters and Google Earth.

\section{Abstract}

Since California's cannabis legalization, localities have played a central role in determining the regulatory terms of where, how and within what legal bounds cannabis cultivation occurs. Siskiyou County, a rural, conservative and majority white county in Northern California, chose not to recognize cannabis cultivation as agriculture. It drew up highly restrictive cannabis cultivation regulations, largely under the purview of law enforcement rather than civil agencies. Hmong-American cultivators, made highly visible through enforcement practices, policy forums and media discourses, have borne the brunt of this regulatory regime. Cannabis policy, especially in its ethnic-racial dimensions, has become symbolic of broader anxieties about cultural and agricultural change. We employed ethnographic methods to research the formation and enforcement of Siskiyou's restrictive cannabis cultivation regulations, and their differential effects across local populations. We found that the county's law enforcement-first regulatory approach blurred civil and criminal lines, made some cultivators more visible and vulnerable to enforcement, and promoted criminalizing approaches to cultivators, even among civil regulatory agencies. These developments hinder the ability of agencies (including the California Department of Food and Agriculture and the California Department of Fish and Wildlife) to ameliorate negative social and ecological effects of cannabis cultivation through civil regulation, support and services.

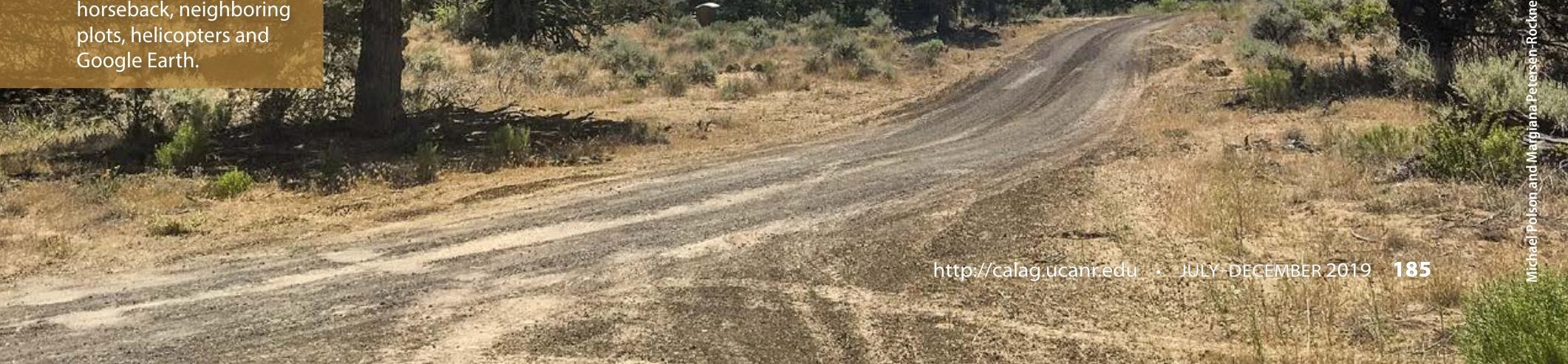


With the passage of Proposition 64 (see page 106), state voters elected to integrate cannabis into civil regulation. The California Department of Food and Agriculture (CDFA) oversees state-licensed cannabis cultivation and defined it as agriculture (California State Legislature 2017a). Prior to the possibility of state licensure for cultivators, however, counties can decide on other designations and implement strict limitations. In effect, local governments have become gatekeepers to whether and how cultivation of personal, medical or recreational cannabis can occur and the repercussions of noncompliance. When cannabis is denied a consistent status as agriculture, despite being a legal agricultural commodity according to the state, localities can determine who counts as a farmer and who is considered compliant, noncompliant and even criminal.

In Siskiyou County's unincorporated areas, the Sheriff's Office now arbitrates between the effectively criminal and agricultural. Paradoxically for this libertarian county, the furor around cannabis has seen calls for government intervention, and has led to officials passing highly stringent cannabis cultivation regulations that have been enforced largely by law enforcement, muddying the line between noncompliance and criminality. These strict regulations produced a situation where "not one person" has been able to come into compliance, according to a knowledgeable government official. Nonetheless, at the sheriff's urging, Siskiyou declared a "state of emergency" due to "nearly universal non-compliance" (Siskiyou County 2017b), branding cannabis cultivation an "out-of-control problem."

Such a strong reaction against cannabis can be understood in terms of cannabis's potential to reorganize Siskiyou's agricultural and economic landscape. According to some estimates, there are now approximately twice as many cannabis cultivators as noncannabis farmers and ranchers in Siskiyou (Siskiyou County 2017b; St. John 2017; USDA NASS 2017), a significant change from just a few years ago. Although cannabis has been cultivated in this mostly white county for decades, since 2015 it has become associated with an in-migration of Hmong-American cultivators. (Though interviewees referred to themselves often as "Hmong," we use the hyphenated descriptor to mark their status as U.S. citizens and residents.) Made highly visible through enforcement practices, policy forums and media discourses, Hmong-Americans have become symbolically representative of the "problem." This high visibility, however, obscures a deeper issue, what Doremus et al. (2003) see as a nostalgic, static conception of rural culture that requires defensive action as a bulwark against change. Such locally-defined conceptions need to be understood (Walker 2003), especially in how they are defined and defended and what effects they have on parity among farmers growing different types of crops.

Our goals in this study were to consider the consequences of an enforcement-first regulatory approach - a common regulatory strategy across California - and its differential effects across local populations. Using Siskiyou County as a case study, we paid attention to the public agencies, actors and discourses that guided the formation and enforcement of restrictive cannabis cultivation regulations as well as attempts to ameliorate perceptions of racialized enforcement. This study attends to novel postlegalization apparatuses, their grounding in traditional definitions of (agri)culture and the ways these dynamics reactivate prohibition.

\section{Ethnographic study}

We used qualitative ethnographic methods of research, including participant observation and interviews. In situations of criminalization, which we define not only as the leveling of criminal sanctions but being discursively labeled or responded to as criminal-like (Schneider and Schneider 2008), quantitative data can be unreliable and opaque, which necessitates the use of qualitative ethnographic methods (Clatts et al. 2002; Ferrell and Hamm 1998).

In 2018-2019, we talked to a wide range of people - including cannabis growers from a diversity of ethnic backgrounds, government officials, businesspeople, subdivision residents, farm service providers, medical cannabis advocates, realtors, lawyers, farmers and ranchers, and, with the assistance of a Hmong-American interpreter, members of the Hmong-American community. We also analyzed public records and county ordinances, Board of Supervisors meeting minutes and audio (meetings from 2015 to 2018), Sheriff's Office press releases and documents, related media articles and videos, and websites of owners' associations in the subdivisions where cannabis law enforcement efforts have focused.

Some cannabis cultivators regarded us suspiciously and were hesitant to speak openly, an unsurprising phenomenon when researching hidden, illegal and stigmatized activities, like "drug" commerce (Adler 1990; Bourgois 1995; Moore 1993; Northcote and Moore 2010). This circumspection was most intense among Hmong-American growers on subdivisions, who had been particularly highlighted through enforcement efforts and local, regional and national media accounts linking their relatively recent presence in Siskiyou to cannabis growing.

Human subjects in this research are protected under the Committee for Protection of Human Subjects, protocol number 2018-04-1136 (approved May 21, 2018), of the Office for Protection of Human Subjects at UC Berkeley.

\section{(Agri)culture and cannabis}

Siskiyou is a large rural county located in the mid-Klamath River basin in Northern California (fig. 1). Since the mid-19th century, inmigrants have historically engaged in agriculture, predominantly livestock grazing and hay production, and natural resource extraction, primarily timber and mining (Doremus et al. 2003). Public records demonstrate that although the value of the county's agricultural output and natural resource extraction is declining, these cultural livelihoods still shape the area's dominant rural values of self-reliance, hard work and property rights (CED 2012; Doremus et al. 2003; NoRTEC 2016). For instance, one county document stated that Siskiyou's cultural-economic stability depends on nonintervention from "outside groups and governments" and residents should be "subject only to the rule of nature and free markets" (Siskiyou County 1996, 25). Another document, a "Primer for living in Siskiyou County" from the county administrator, outlined "the Code of the West" for "newcomers," asserting that locals are "rugged individuals" who live "outside city limits," and that the "right to be rural" protects and prioritizes working agricultural land for "economic purpose[s]" (Siskiyou County 2005).

We heard a common refrain that localities will eventually succumb to the allure of a taxable, profitable cannabis industry. Indeed, interviewees in Siskiyou universally reported economic contributions from cannabis cultivation, especially apparent in rising property values and tax rolls and booming business at horticultural, farm supply, soil, generator, food and hardware stores (see Stoa 2018). However, a belief in an inevitable free market economic rationality may underestimate the deep cultural logics that have historically superseded economic gains in regional resource conflicts (Doremus et al. 2003). As one local store 
owner told us, "I'd give up this new profit in a heartbeat for the benefit of our society."

Many long-time farming and ranching families remain committed to agricultural livelihoods for cultural reasons (Reinhart and Barlett 1989), even as the economic viability of family farms is threatened by increasing farmland financialization (Fairbairn 2014), corporate consolidation (Hossein and Elsheikh 2015) and biophysical decline (Pathak et al. 2018). Many interviewees felt that the recent rapid expansion of county cannabis cultivation and corresponding demographic changes were a visible marker of broader tensions of (agri)cultural continuity and endangerment. As the sheriff expressed, cannabis cultivation would "jeopardize our way of life ... [and] the future of our children” (SCSO 2017a).

This sense of cultural jeopardy (see Tarlock 1999), echoed by numerous interviewees, materialized in a range of negative quality-of-life comments about cannabis cultivation: noisy generators, increased traffic, litter and blighted properties, and unsafe conditions for residents. Noncannabis farmers also reported farm equipment and water theft, livestock killed by abandoned dogs, wildfire danger, illicit chemical use and poisoned wildlife.

Some noncannabis farmers expressed a sense of regulatory unfairness - that their farms were subject to onerous water and chemical use regulations while cannabis growers “don't need to follow the government's regulations.” Enabling cannabis cultivators to pursue state licensure would facilitate just such civil regulation, but some feared that regulating this crop as agriculture would threaten "the loss of prime agriculturally productive lands for traditional pursuits" (Siskiyou County 2017a, 4). If nothing less than the county's culture and agricultural order were considered at stake, it is no wonder that absolute, even prohibitionist, solutions emerged in Siskiyou, with the Sheriff's Office having a central role in defending local (agri)culture.

\section{Early, collaborative regulation}

Siskiyou's sparsely populated landscape has been home to illegalized cannabis cultivators at least since the late 1960s, largely in remote, forested, and public lands in the western part of the county. Medical cannabis's decriminalization in 1996 inaugurated a modest expansion of cannabis gardens throughout the county (fig. 2). However, for the next 19 years, Siskiyou did not establish regulations for medical cannabis, in line with locally dominant ideologies of personal freedoms and property rights. Instead, the county relied on de facto management of cultivation by law enforcement and the court system's strict interpretation of state law (Boerger 2007).

In 2015 , informed by public workshops held by the Siskiyou County Planning Division, supervisors passed the county's first medical cannabis ordinance, which seemingly balanced concerns of medical cultivators and other county residents. Regulation would be overseen by the Planning Division, which placed conditions on cultivation (e.g., property setbacks), limited plant numbers to parcel size and would establish an administrative abatement and hearing process for complaints.

The Planning Division, however, had been without code enforcement officers since 2008 budget cuts. Though the county authorized the hiring of one civil code officer in 2015, the Sheriff's Office felt that the Planning Division "needed outside help" and moved to assist. Soon, the county's limited abatement capacities were overwhelmed by vigorous enforcement and a wave of complainants. County supervisors, responding to the sheriff's 2015 reports on the "proliferation" of cannabis gardens on private property, moved to heighten penalties for code violations, place numerous new restrictions on indoor growing and ban all outdoor growing (SCSO 2015; table 1).

These strict county measures, which discarded and replaced publicly developed regulations, stoked reaction. When the Siskiyou County Board of Supervisors met in December 2015 to vote on these measures, advocates and cultivators presented 1,500 signatures to

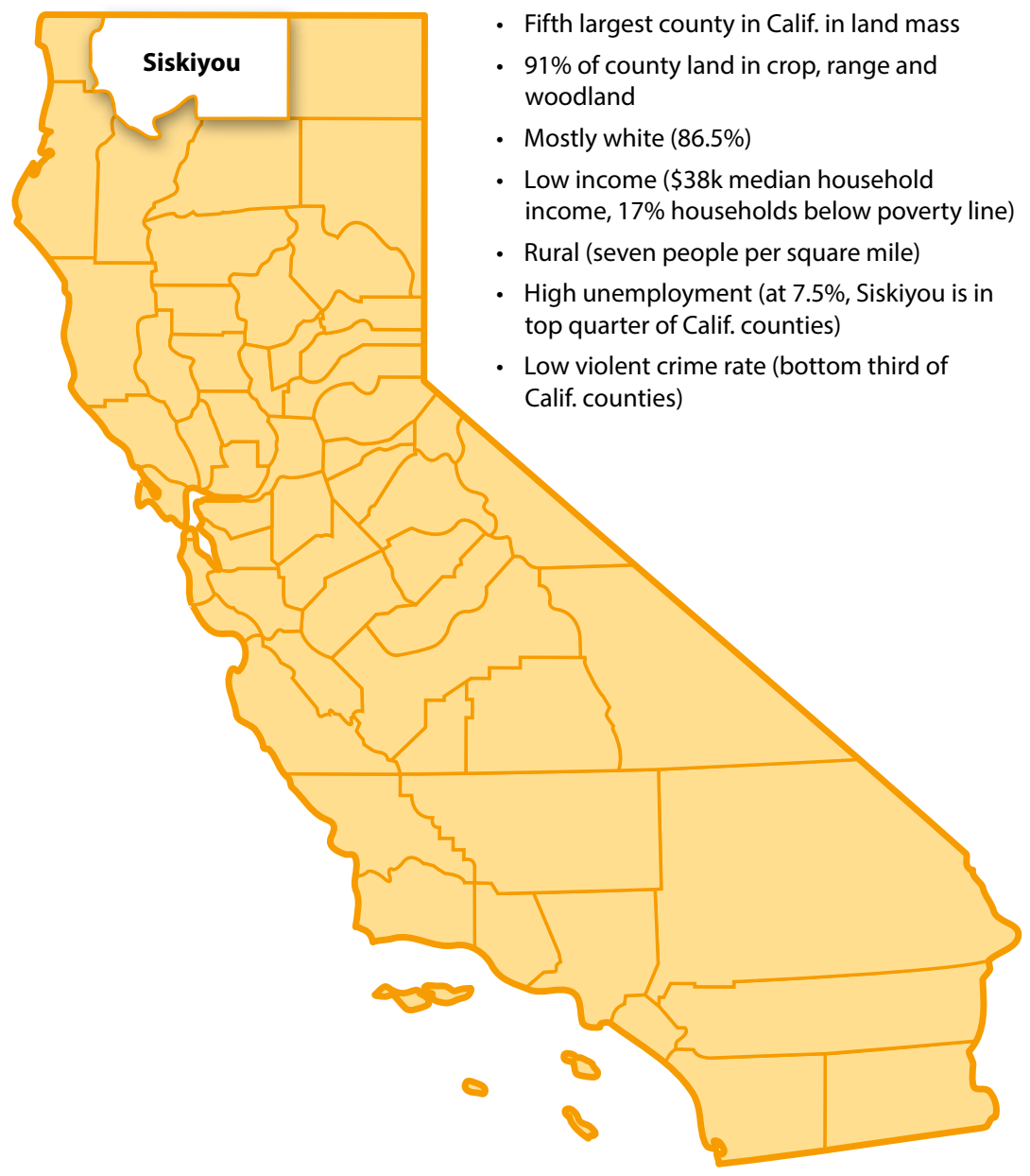

FIG. 1. Siskiyou County is a large, rural California county. Its residents are mostly white. Compared to other California counties, it has relatively high unemployment, a low violent crime rate and low median household income. 
FIG. 2. Timeline of cannabis activities in Siskiyou County.

1996
2004
2014
$2014-2015$
March 2015
April 2015
2015

\section{Late 2015 \\ September 2015}

December 2015

\section{January 2016}

March 25, 2016

May 25, 2016

June 5, 2016

June 7, 2016

July 2016

September 2016

November 2016

Winter 2016-2017

June 2017

June-December 2017

July 2017

August 8, 2017

August 2017

September 5, 2017

September 16, 2017

September 2017

October 2017

December 2017

January 2018

April 2018

May 2018

Summer 2018

June 2018

August 2018

June 2019

Voters approve Proposition 215, Compassionate Use Act.

Medical Marijuana Program Act provides statewide guidance for medical marijuana.

Siskiyou Alternative Medicine founded to advocate for medical marijuana rights.

Siskiyou Planning Division holds public workshops about medical cannabis.

Agricultural commissioner states cannabis is not agriculture (Siskiyou County 2015).

Siskiyou's first medical marijuana regulations passed.

Interviewees describe and property records show increased Hmong-American in-migration to the county (from other states or California towns).

Hmong-Americans begin to attend county Board of Supervisor meetings, and organize countywide advocacy. Medical Marijuana Regulation and Safety Act passes, regulating medical cannabis businesses at state level.

Siskiyou's Board of Supervisors bans outdoor cultivation and tightens cannabis ordinances and enforcement; advocates present 1,500 signatures in opposition.

Advocates collect 4,000 signatures to place stricter ordinances on 2016 county voter ballot.

Sheriff's Office releases strategic plan with state and federal agencies to "attack illegal grows" and enforce civil regulations.

Sheriff's Office releases study reporting rising crime rates and attributes them to "the \#1 public enemy to Siskiyou citizens ... criminal marijuana cultivation."

Sheriff's Office accompanies state voter fraud investigators to properties of Hmong-Americans, resulting in voter intimidation lawsuit.

Siskiyou voters approve more restrictive cannabis cultivation ordinances.

Sheriff's Office founds Siskiyou Interagency Marijuana Investigation Team with district attorney, soon enlists National Guard, Cal Fire and California Highway Patrol in cannabis enforcement activities.

Siskiyou Alternative Medicine brings lawsuit against county alleging constitutional violations and harassment by Sheriff's Office.

California and Siskiyou voters approve Proposition 64, Adult Use of Marijuana Act (AUMA) legalizing recreational cannabis.

Three people die of carbon monoxide in substandard housing on cannabis grow sites.

State merges medical and recreational regulatory systems in the Medical and Adult Use Cannabis Regulation and Safety Act (MAUCRSA).

Local, regional and national papers highlight conflict between Hmong-Americans and law enforcement.

Planning Division submits study to supervisors on potential for commercial recreational and medical regulatory system, recommends against agricultural zoning.

Siskiyou passes moratorium on all recreational and medical cannabis commerce.

Cultivators in cannabis operation arrested for bribing sheriff for exemption from county cannabis ban.

Siskiyou issues state of emergency declaration regarding cannabis cultivation.

CDFA declares "cannabis is an agricultural product."

Hmong-American voter intimidation lawsuit against county dismissed.

City of Mt. Shasta, in Siskiyou, passes municipal ordinance allowing cannabis commerce.

Siskiyou's City of Dunsmuir passes municipal ordinance allowing cannabis commerce.

California's cannabis commerce regulations take effect.

Siskiyou's City of Weed passes municipal ordinance allowing cannabis commerce.

Sheriff's Office hosts first Hmong-American and County Leaders Town Hall Meeting.

Sheriff's Office continues building enforcement alliances with other agencies (County Animal Control Department, California Department of Toxic Substances Control, State Water Resources Control Board, California Department of Fish and Wildlife).

Sheriff's Office hires first Hmong-American sheriff's deputy in Siskiyou.

Supervisors tighten penalties, timeframes and appeal processes for civil code violations, and formalize and expand powers for enforcement officers.

County implements permanent prohibition of all commercial cannabis activity in unincorporated areas. 
forestall its passage, a supermajority (110-6) of attending residents indicated opposition, and supervisors had to curtail 3 hours of public comment to vote. Despite this showing, supervisors passed the restrictive measures, prompting cannabis advocates to collect 4,000 signatures in 17 days to place the approved ordinances on the June 2016 ballot. Meanwhile, the Sheriff's Office enforced the new stricter regulations (SCSO 2016a).

\section{Blurring civil and criminal lines}

The Sheriff's Office assumption of code enforcement blurred the line between noncompliance with civil codes and criminal acts. Stricter ordinances, still in effect in Siskiyou, created a broad, nearly universal category of "noncompliance." No one we interviewed, including officials at the Planning Division and Sheriff's Office, knew of a single cultivator officially in compliance. One interviewee estimated that growing 12 indoor plants (the maximum allowed for personal, nonmarket use) would cost $\$ 40,000$ in physical infrastructure, in addition to numerous licensing and inspections requirements, effectively prohibiting self-provisioning.

The Sheriff's Office notified the public that it would initiate criminal charges against "noncompliant" cultivators, specifically those suspected of cultivation for sale (e.g., growing an amount "reasonably inconsistent with" medical needs), child endangerment (e.g., presence of a minor near a Schedule I drug) (SCSO 2015) or suspected drug trafficking (the criteria for which includes being in possession of too much unlicensed cannabis) (SCSO 2016b). Since the county regulations produced a situation where no one could comply, law enforcement could effectively criminally pursue any cultivator.

The slippage from civil noncompliance to criminality was mirrored in enforcement practices. Investigations were "complaint driven," meaning not only that warrants could be issued in response to disgruntled neighbors upset about a barking dog on a cultivation site, as one person reported, but that police officers could serve as a kind of permanent, general complainant and take "proactive action" when they spotted code violations (SCSO 2015). Administrative warrants allowed deputies to enter properties with a lower evidentiary bar than they would have needed for criminal warrants, leading one patients rights group - Siskiyou Alternative Medicine - to file a lawsuit alleging county violations of Fourth Amendment protections against unreasonable search and seizure (later dismissed because plaintiffs were fearful of identifying themselves).

In effect, cannabis's criminal valences in the county endured through California's shift of cannabis from criminal to civil provenance. Formerly illegal activities continued to be formally or informally treated as criminal matters, as researchers have noted with other stigmatized activities and groups, for example, after the decriminalization of sex workers in Mexico (Kelly 2008). Also, enforcement of civil matters can lead to substantive criminalization when those matters are stigmatized, as in the regulation of homelessness (Walby and Lippert 2012). While it is not unique for police officers to enforce civil codes, what is unique in Siskiyou County is the assumption of the entire civil process (complaints, inspection, abatement, sanctions) under the sheriff's authority.

\section{Visibility, race and crime}

To understand how this civil process became criminally inflected, in a county that voted for statewide cannabis legalization in 2016, one must first understand significant contextual shifts in who was growing cannabis where - and the challenge this posed to

TABLE 1. Cannabis-related ordinances passed by Siskiyou County since 2015

\begin{tabular}{|c|c|c|}
\hline Passed & Ordinance title & Impact \\
\hline $04 / 2015$ & $\begin{array}{l}15-04 \text { Medical Marijuana } \\
\text { Cultivation (1) }\end{array}$ & $\begin{array}{l}\text { Established plant allowance based on parcel size, } \\
\text { some property requirements, and an abatement/ } \\
\text { hearing process for complaints. }\end{array}$ \\
\hline $12 / 2015$ & $\begin{array}{l}\text { 15-18 Medical Marijuana } \\
\text { Enforcement }\end{array}$ & $\begin{array}{l}\text { Medical grows must hold license. Civil penalty of } \\
\text { code violation with daily fee. Option for hearing. } \\
\text { Voters approved in June } 2016 \text {. }\end{array}$ \\
\hline $12 / 2015$ & $\begin{array}{l}15-19 \text { Medical Marijuana } \\
\text { Cultivation (2) }\end{array}$ & $\begin{array}{l}\text { Restrictive set of permitting, inspection and } \\
\text { property requirements. Limited plants to } 12 \text { per } \\
\text { parcel. Voters approved in June } 2016 \text {. }\end{array}$ \\
\hline $08 / 2017$ & $\begin{array}{l}\text { 17-11 Moratorium on } \\
\text { Commercial Cannabis } \\
\text { Activities (and its extension } \\
17-12 \text { in } 09 / 2017 \text { ) }\end{array}$ & $\begin{array}{l}\text { Prohibits commercial production, whether or not } \\
\text { profit is intended, for } 1 \text { year. }\end{array}$ \\
\hline 09/2017 & $\begin{array}{l}\text { Local State of Emergency: } \\
\text { Proliferation of Illegal } \\
\text { Cannabis Cultivation }\end{array}$ & $\begin{array}{l}\text { Citing } 2,000+\text { private grows, over } 100,000 \text { plants } \\
\text { seized on public land in } 2016 \text {, and nearly universal } \\
\text { noncompliance allowed the Sheriff's Office to } \\
\text { harness other agency, state and federal resources. }\end{array}$ \\
\hline $12 / 2017$ & 17-14 Cannabis Cultivation & $\begin{array}{l}\text { Amending } 15-19 \text { to extend restrictive requirements } \\
\text { to personal cannabis cultivation. Exemption for } \\
\text { six or fewer plants on private residence in locked } \\
\text { facility not visible from public space. }\end{array}$ \\
\hline $07 / 2018$ & $\begin{array}{l}18-05 \text { Interim Zoning/ } \\
\text { Urgency Extending the } \\
\text { Commercial Cannabis } \\
\text { Moratoriums Currently in } \\
\text { Place }\end{array}$ & $\begin{array}{l}\text { Extended moratorium for second and final year } \\
\text { to allow county time to develop and adopt } \\
\text { permanent ordinance. Passed due to "current and } \\
\text { immediate threat posed by commercial cannabis } \\
\text { land uses." }\end{array}$ \\
\hline 08/2018 & $\begin{array}{l}\text { 18-06 Amending Citation } \\
\text { Procedures for Code } \\
\text { Enforcement Processes } \\
\text { and Fines }\end{array}$ & $\begin{array}{l}\text { Shortened compliance and appeal time from } 14 \\
\text { to } 7 \text { days; expanded fines for some penalties to } \\
\$ 1,000 / \text { day; expanded enforcement officer's power } \\
\text { for immediate citation and discretion to determine } \\
\text { fine amount; required advance deposit for fines } \\
\text { prior to hearing; expanded county's power to place } \\
\text { liens on property for nuisance violations; lowered } \\
\text { bar for violation notifications; enabled county } \\
\text { prosecutors to reduce misdemeanors (with jail } \\
\text { time) to infractions. }\end{array}$ \\
\hline $06 / 2019$ & $\begin{array}{l}\text { 19-07 Commercial Cannabis } \\
\text { Activities Prohibited }\end{array}$ & $\begin{array}{l}\text { "To prohibit, to the greatest extent that is } \\
\text { compatible and consistent with state law, } \\
\text { Commercial Cannabis Activity within the } \\
\text { unincorporated County and to preclude businesses } \\
\text { engaging in such activities from procuring a } \\
\text { business license or a land use entitlement from } \\
\text { the County." }\end{array}$ \\
\hline
\end{tabular}


dominant ideas of land use, agriculture and culture. Since 2014, cannabis gardens have emerged on many of the county's undeveloped rural subdivisions in unincorporated areas of Siskiyou. Subdivided into over 1,000 lots each in the 1960s, these subdivisions contain many parcels that are just a few acres in size and relatively inexpensive. Previously populated mostly by white retirees, squatters and a few methamphetamine users and makers, the parcels were often bought sight-unseen as investments or potential retirement properties, with most remaining unsold and undeveloped until the mid-2010s.

In 2014, these subdivisions became destinations for HmongAmericans from several places, including Minneapolis, Milwaukee and Fresno; many of them cultivated cannabis. The inexpensive, sparsely populated, rural subdivisions enabled Hmong-Americans to live in close proximity to ethnic and kin networks, which multiple interviewees expressed was especially important for elders who had migrated to the United States as refugees after the Vietnam War. The county sheriff estimated that since the mid-2010s around 6,000 Hmong-Americans had moved to Siskiyou, purchasing approximately 1,500 parcels (St. John 2017). In an $86.5 \%$ white county with just 745 noncannabis farms (USDA NASS 2017) and fewer than 44,000 people (US Census Bureau 2017), this constituted a major demographic shift. Hmong-American residents found themselves susceptible to scrutiny by white neighbors and officials.

Cannabis growers in Siskiyou's subdivisions are especially vulnerable to detection. The subdivisions are often sparsely vegetated, dry and hilly, making them not only unproductive as agricultural lands but also highly visible from public roads, horseback, neighboring plots, helicopter and Google Earth. Green screen fencing, wooden stakes, portable toilets, generators, campers, plywood houses, or water tanks and trucks often signal cannabis cultivation but would be necessary for many land uses, especially since many lots are sold without infrastructure like water, sewer or electrical access.

If detection of code violations depends upon visibility, HmongAmericans on subdivisions have been made especially visible and vulnerable to detection. One lawyer, for instance, reported that $90 \%$ of the defendants present at administrative county hearings for code violations in fall 2015, when the first complaint-driven ordinance was put in place, were Hmong-American. One Hmong-American resident reported being stopped by police six times in 3 months (his wife three times) and subjected to unfriendly white neighbors patrolling on horseback for cannabis - one of whom made a complaint for a crowing rooster, a questionable nuisance in this "right to farm" county. Numerous Hmong-Americans and sympathetic whites echoed these experiences. County residents confirmed their antagonism toward Hmong-Americans by characterizing them in interviews and public records as dishonest, thieves, polluters, negligent parents and unable to assimilate, and making other racializing and racist characterizations.

While written regulations and enforcement profess race neutrality, in a nuisance enforcement regime based on visibility, HmongAmericans were more visible than others, leading many to argue that they were being racially profiled. Rhetoric emerging from the county government amplified racial tensions and visibilities. Numerous Sheriff's Office press releases located the "problem" in subdivisions and attributed it to "an influx of people temporarily moving to Siskiyou" (SCSO 2015) who were "lawbreakers" from "crime families" with "big money" (SCSO 2016a) and who threatened "our way of life, quality of life, and the health and safety of our children and grandchildren" (SCSO 2016b).
Just 2 days before the June 2016 ballot on the strict cannabis ordinances, state investigators responded to county reports that newly registered Hmong-American voters might be fraudulent or coerced by criminal actors and visited Hmong-American residences to investigate, accompanied by sheriff's deputies (who some reported had guns drawn). The voter fraud charges were later countered by a lawsuit alleging racially motivated voter intimidation; the suit was eventually dismissed for failing to meet the notoriously difficult criteria of racist intent. The raids may have discouraged some Hmong-Americans from voting, charges of fraud may have boosted anticannabis sentiment, and, one government official explained, "creative balloting" measures enabled some municipal voters in conservative localities to vote while others in more liberal places could not.

The voter fraud charges, raids and legal contestation drew widespread media attention that further linked Hmong-Americans and cannabis. Amidst these now-overt racial tensions, the restrictive June 2016 ballot measure passed, allowing the Sheriff's Office to gain full enforcement power over the "\#1 public enemy to Siskiyou citizens ... criminal marijuana cultivation” (SCSO 2016b).

Shortly after the June 2016 ballot measure affirmed stricter regulations, the Sheriff's Office formed the Siskiyou Interagency Marijuana Investigation Team (SIMIT) with the district attorney to "attack illegal marijuana grows" (SCSO 2016a) "mostly" around rural subdivisions (SCSO 2017b). Within a month, SIMIT had issued 25 abatement notices and filed 20 criminal charges, in addition to confiscating numerous plants. Meanwhile, the Planning Division's role had diminished - code enforcement officers were relegated to addressing violations not directly related to cannabis (illegal encampments, debris piles, etc.).

\section{Postlegalization prohibition}

The November 2016 state legalization of recreational cannabis prompted Siskiyou to examine a possible licensure and taxation system for local growers (Siskiyou County 2017a). Amidst sustained, vocal opposition, the proposal stalled for several reasons that further aggravated cultural and racial tensions: A key proponent of licensure was discovered to be running an unauthorized grow, three HmongAmericans died of carbon monoxide poisoning due to heaters in substandard housing, and a cannabis cultivation enterprise run by two Hmong-Americans attempted to bribe the sheriff.

These developments were interpreted not as outcomes of restrictive regulations and criminalizing strategies, but as proof that, in the words of one supervisor, regulation was impossible until the county could "get a handle on the illegal side of things." The sheriff encouraged this interpretation, arguing in an interview that statewide legalization was "just a shield that protects illegal marijuana" and efforts to regulate it would always be subverted by criminals.

This antiregulatory logic prevailed in August 2017 when the county placed a moratorium on cannabis commerce. Still, the sheriff argued for stronger powers, citing an "overwhelming number of cannabis cultivation sites," which, according to the Sheriff's Office, continued to "wreak ... havoc [with] potentially catastrophic impacts" across the region (SCSO 2017b). Just 1 month later, at the sheriff's urging, the Siskiyou Board of Supervisors declared a "state of emergency" aimed at garnering new resources and alliances to address the cannabis cultivation problem. Soon, the Sheriff's Office enlisted the National Guard, Cal Fire and the California Highway Patrol in enforcement efforts, and, by 2018, numerous other agencies joined, including 
the Siskiyou County Animal Control Department, California Department of Toxic Substances Control, State Water Resources Control Board, California Department of Fish and Wildlife and a CDFA inspection station. These alliances multiplied the civil and criminal charges cultivators might face (e.g., toxic dumping, wildlife endangerment).

Ironically, California's cannabis legalization has enabled a kind of multi-agency neoprohibitionism at the county level, one that reinforces older criminal responses with new civil-administrative strategies and authorities. The need to "get a handle" might be regarded as a temporary emergency measure, but it may also propagate new criminalizing methods and institutional configurations. The more enforcement occurs, the bigger the problem appears, requiring more resources and leading to a logic of escalation symmetrical to the much-critiqued War on Drugs (Heyman 1999; Johns 1992; Polson 2018). And the more cannabis cultivators are viewed as criminal, the less likely they are to be addressed as citizens, residents and farmers.

\section{Cultural misunderstandings}

Given concerns about biased county policy and enforcement, the Sheriff's Office held the first HmongAmerican and Siskiyou County Leader Town Hall in May 2018 to "foster a closer, collaborative relationship with members of the Hmong-American community," exchange information about Hmong and Siskiyou culture and educate attendees on county policies (SCSO 2018). According to public records, racial tensions surfaced at this meeting when some white participants expressed that "our county" had been "invaded" and that Hmong-Americans were not fitting into local cultural norms (Shulman 2018). Meeting leaders - both government officials and Hmong-Americans - however, identified cultural misunderstanding, rather than criminalization and racialized claims by whites on what constitutes local culture, as the core problem to be addressed. (Accordingly, the Sheriff's Office hired a Hmong-American deputy to address perceptions of racialized enforcement and work more closely with the Hmong-American community, yet enforcement-first policies that disproportionately affect Hmong-Americans have continued.)

"Misunderstanding" was an inadequate framing, given that Hmong-Americans had attempted to make themselves understood by attending public meetings, forming advocacy groups, signing petitions, demanding interpreters and administrative hearings, and registering to vote since their arrival in Siskiyou. At the 2018 town hall, and numerous prior meetings, they emphasized their status as legitimate community members - veterans, citizens, consumers of county goods, local property owners, "good" growers and medical users - not nuisances, criminals, foreigners or outsiders. In interviews and public forums many Hmong-American cultivators expressed a desire to comply with the rules.
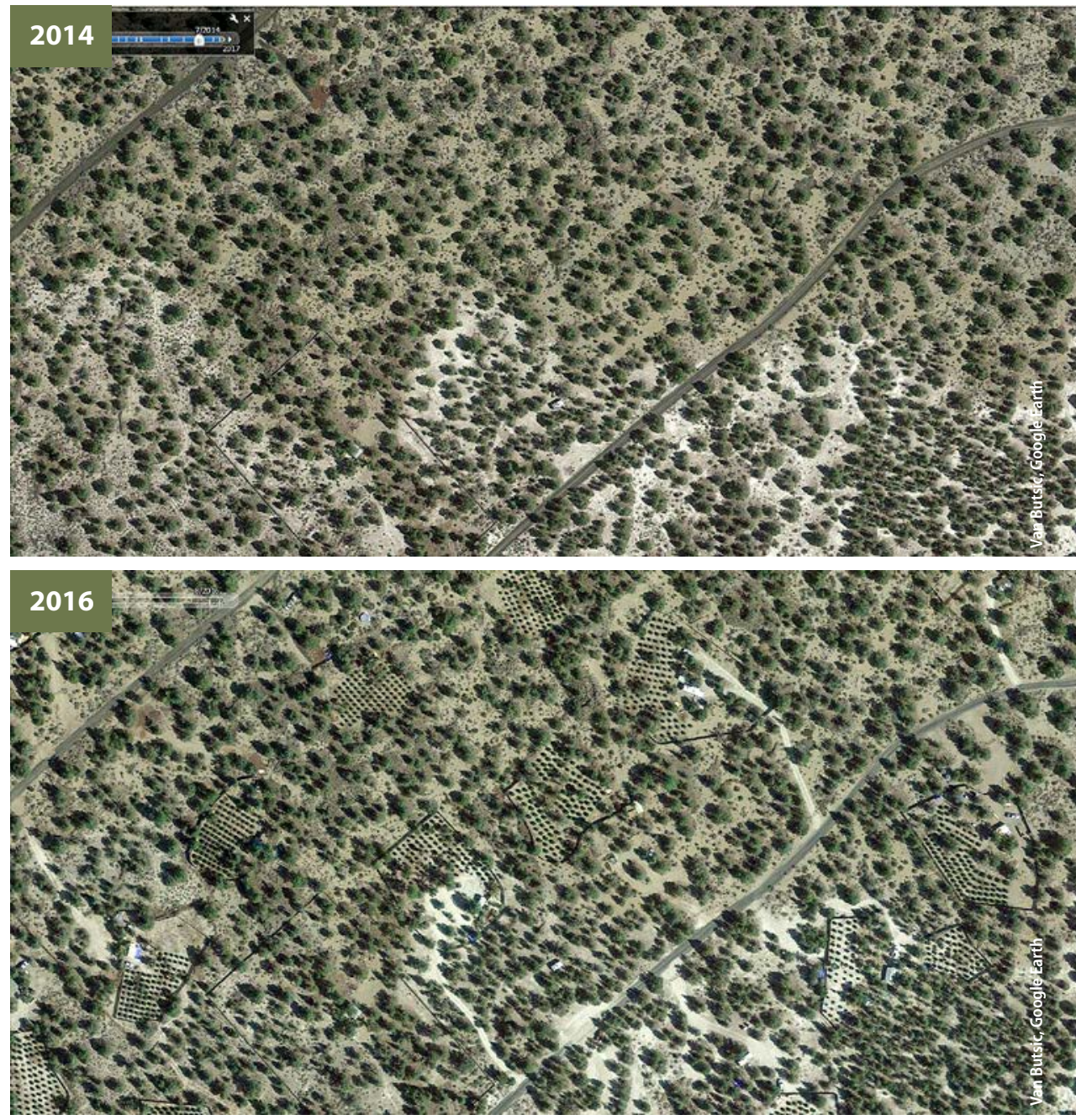

Their efforts, however, they said, were frustrated not only by linguistic and cultural differences, but also understaffed and underfunded permitting, licensing and community services agencies. (The Sheriff's Office continues to consume the majority of the general fund.) Images from Google Earth show the establishment of new cannabis cultivation sites between 2014 and 2016 at a Siskiyou County subdivision.
Hmong-American cultivators routinely told us about their desires to settle down, build homes and plant other crops. "I'm growing watermelons, pumpkins and tomatoes," one cultivator told us, but he was waiting for a permit to build his house, a process another interviewee reported took 3 years.

Though the town hall meeting sought to address cultural misunderstanding, this framing overlooks how misunderstanding - of Hmong-Americans or cannabis producers generally - is produced by criminalizing enforcement practices. Properties given as gifts in the Hmong-American community were seen as evidence of criminal conspiracy, not generous family assistance; land financing networks evidenced drug trafficking organizations, not kin-based support and weak credit access; repetitive farm organization patterns suggested "organized crime" (SCSO 2016b), not ethnic knowledge-sharing circuits. When Hmong-Americans, leery of engagement with government agencies and unfriendly civic venues, self-provisioned services, 
including firefighting teams, informal food markets and neighborhood watches, these actions were taken to confirm suspicions that they could not assimilate. Now that some Hmong-Americans are considering, or already are, moving away in response to county efforts, the sheriff's prior description of them as temporary residents seems prophetically manufactured.

\section{Disparities and uneven development}

These stigmatizing views of Hmong-American cultivators affect all cannabis growers. Anticannabis pressure creates a precarious state of impermanence - a season's crop might be destroyed, infrastructure confiscated and investments of limited resources lost at any moment, disallowing longer-term investments. The impermanence makes noncompliance and deleterious environmental and health effects more likely, thereby perpetuating perceptions of cannabis cultivators as nuisances and dangers.

As enforcement makes private land cultivation more risky, cultivators move "back up the hill," namely onto ecologically sensitive public lands, thus substantiating characterizations of cannabis growers as criminal polluters. These stigmas even spread to county residents who do not grow cannabis themselves but if perceived to assist cannabis cultivation can face social sanctions. One agriculturalist reported receiving death threats after selling water to cannabis cultivators.

Meanwhile, well-resourced cultivators have an advantage over small-scale producers. They can protect their crops from visibility and complaints by concealing them on large plots of

Ironically, California's cannabis legalization has enabled a kind of multi-agency neoprohibitionism at the county level. land or inside physical infrastructures (like warehouses); and for white growers there is the anonymity of not being marked as ethnically different and therefore subject to heightened scrutiny. Greater access to capital, land and racial privileges insulates some from visibility and criminalization, resulting in uneven development and disparities in California's expanding cannabis industry. Additionally, jurisdictions like the Siskiyou municipalities of Mt. Shasta and Weed are welcoming regulated cannabis commerce, thus capitalizing on its expulsion from the rest of Siskiyou and benefiting entrepreneurs with social capital and network access to successfully navigate complex public regulatory systems.

\section{Agricultural leadership}

After a century of cannabis's criminal exclusion in California, state voters have elected to integrate cannabis farmers into civil regulation. An important facet of evolving cannabis regulations is local determination. As one interviewee pointed out, a 1-acre farm might be permitted in rural San Joaquin County but would not make sense in downtown San Diego. Yet, when cannabis cultivation is disqualified from consideration as agriculture by localities, as it has been in Siskiyou County, it can be substantively recriminalized and placed beyond the regulatory reach of civil institutions. Prohibitionist strategies that blur lines between civil and criminal enforcement lead to penetrating forms of visibility and vulnerability that produce inequity and disparity. The result, as this case illustrates, can be a narrow, exclusive definition of agriculture that affirms dominant notions of land use and community.

The definition of cannabis cultivation as agriculture by the CDFA creates an opportunity for service providers and regulators - including agricultural institutions, public health departments and environmental agencies - to craft programs and policies that openly address the negative impacts of production. Owley $(2018,1,675)$ advises that "if we treat cultivation of marijuana the same as we treat cultivation of other agricultural crops, we gain stricter regulation of the growing process, including limits on pesticide usage, water pollution, wetland conversion, air pollution, and local land-use laws." Presently, however, many agencies are being enlisted in locally crafted criminalizing efforts, thus limiting their ability to work cooperatively with cultivators and address issues through customary civil abatement processes. Though unregulated cannabis cultivation can pose threats to public health, safety and welfare, police enforcement is only one of many possible ways to address it.

Siskiyou's cannabis cultivators experience familiar agricultural challenges around access to land, water and credit. These challenges are amplified without technical assistance or institutional support. If recognized statewide as farmers, these cultivators would be better positioned to access agricultural training and support services, thus addressing ecological and social concerns around cannabis production. Additionally, new cannabis cultivators might be considered "beginning" farmers according to the CDFA, and minority farmers, including Hmong-Americans, who experience poverty at twice the national rate (Pew Research Center 2015), would be considered "socially disadvantaged" under the California Farmer Equity Act of 2017 (California State Legislature 2017b). Farmers with these designations would, in fact, be prioritized for technical assistance and support from farm service providers if, that is, they were recognized as farmers.

Uniformly treating cannabis cultivation as (legal) agriculture would also help enable the collection of accurate and robust data by researchers. This information base is necessary if agricultural institutions are to take an assistive and educational orientation toward cannabis farmers. Continued enforcement tactics that amplify distrust, frustration and confusion will further hinder data collection (by academics, journalists, government officials, etc.), leaving little basis to understand basic dynamics of complex, interdisciplinary systems 
like agriculture (Gianotti et al. 2017). In a criminalized situation, it is inevitable that information is metered and brokered by community leaders in ways that inhibit full understanding of cannabis cultivation.

We suggest, for all these reasons, that a decisive break with enforcement-led, prohibitionist trajectories is needed and that agricultural institutions lead civil policy development and support farmers who cultivate cannabis. Agricultural service providers could play a leadership role in addressing the pressing needs of farmers - both those impacted by and engaging in cannabis cultivation. Yet, UC Agriculture and Natural Resources (UC ANR) Cooperative Extension advisors, for instance, consistently report that they are currently prohibited from engaging with cannabis issues (see issue introduction). Additionally, many county-based agricultural commissions, Siskiyou County's included, feel that cannabis is not an agricultural enterprise and therefore do not see its cultivators as their clientele.

Without leadership from agricultural institutions and agencies, the expanding cannabis cultivation industry is left to develop unevenly across the state - with wealthy private interests capitalizing in some locales while vulnerable and unregulated growers may retreat, to avoid criminalization, into ecologically sensitive areas. UC ANR and CDFA have an opportunity to fulfill their missions and facilitate, for a burgeoning farming population, greater parity in farmer rights, capacities and resource access. $\mathrm{CA}$

M. Petersen-Rockney is Ph.D. Candidate and M. Polson is Ciriacy-Wantrup Postdoctoral Fellow in Natural Resource Economics and Political Economy, Department of Environmental Science, Policy, and Management, UC Berkeley.

We would like to thank Daisy Xiong for her assistance with interpreting during data collection for this article and Dr. Van Butsic for the use of images and research support.

\section{References}

Adler P. 1990. Ethnographic research on hidden populations: Penetrating the drug world. In The Collection and Interpretation of Data from Hidden Populations. Lambert EY (ed.). Rockville, MD: National Institute on Drug Abuse. p 96-111.

Boerger P. 2007. Medical marijuana violation arrests soar. Sturgis Journal, June 26. www. sturgisjournal.com/x93174479

Bourgois PI. 1995. In Search of Respect: Selling Crack in El Barrio. New York: Cambridge Univ Pr. California State Legislature. 2017a. AB 133, Chapter 253, Section 6, Business and Professions Code 26069a. https:// leginfo.legislature.ca.gov/ faces/billNavClient.xhtml?bill_ id $=201720180$ AB133

California State Legislature. 2017b. California Farmer Equity Act 2017 (AB 1348). https:// leginfo.legislature.ca.gov/ faces/billTextClient.xhtml?bill_ id $=201720180$ AB1348

[CED] Center for Economic Development. 2012. Regional Economic and Demographic Profile. www.co.siskiyou.ca.us/ sites/default/files/fileattach ments/restricted_updates/ page/2671/region_data_profile. pdf

Clatts M, Welle D, Goldsamt L, Lankenau S. 2002. An ethnoepidemiological model for the study of trends in illicit drug use: Reflections on the 'emergence' of crack injection. Int J Drug Policy 13(4):285-95.

Doremus H, Law B, Tarlock AD. 2003. Fish, farms, and the clash of cultures in the Klamath Basin. Ecol Law Quart 30:350.
Fairbairn M. 2014. 'Like gold with yield': Evolving intersec tions between farmland and finance. J Peasant Stud 41(5):777-95. doi:10.1080/0306 6150.2013 .873977

Ferrell J, Hamm MS. 1998. Ethnography at the Edge: Crime Deviance, and Field Research. Boston: Northeastern University Press.

Gianotti AS, Harrower J, Baird G, Sepaniak S. 2017. The quasilegal challenge: Assessing and governing the environmental impacts of cannabis cultivation in the North Coastal Basin of California. Land Use Policy 61:126-34

Heyman J. 1999. State escalation of force: A Vietnam/U.S.Mexico border analogy. In States and Illegal Practices. Heyman J (ed.). Oxford: Berg Publishing. p 285-314.

Hossein A, Elsheikh E. 2015. The US Farm Bill: Corporate Power and Structural Racialization in the US Food System. Haas Institute for a Fair and Inclusive Society. https://haasinstitute. berkeley.edu/global-justice/ glocal-food-systems/farm-billreport-corporate-power-andstructural-racialization-us-foodsystem

Johns CJ. 1992. Power, Ideology and the War on Drugs: Nothing Succeeds Like Failure. New York: Praeger.

Kelly P. 2008. Lydia's Open Door: Inside Mexico's Most Modern Brothel. Berkeley: Univ California $\mathrm{Pr}$.

Moore D. 1993. Ethnography and illicit drug use: Dispatches from an anthropologist in the "field." Addict Res Theory 1(1):11-25.
[NoRTEC] Northern Rural Training and Employment Consortium. 2016. Siskiyou County Labor Market Profile and Industry/Sector Analysis. www. ncen.org/images/documents/ Imi/regional-profiles/Siskiyou\% 20County\%20Labor\%20 Market\%20and\%20IndustrySector\%20Analysis.pdf

Northcote J, Moore D. 2010. Understanding contexts: Methods and analysis in ethnographic research on drugs. In Addiction Research Methods. Miller $\mathrm{P}_{\text {, }}$ Strang J, Miller P (eds.). Oxford: Wiley-Blackwell. p 287-98.

Owley J. 2018. Unforeseen land uses: The effect of marijuana legalization on land conservation programs. UC Davis Law Rev 51:1673-1716. https://digital commons.law.buffalo.edu/ articles/916

Pathak T, Maskey M, Dahlberg J, et al. 2018. Climate change trends and impacts on California agriculture: A detailed review. Agronomy 8(3):25. doi:10.3390/agronomy8030025

Pew Research Center. 2015 Hmong in the U.S. Fact Sheet www.pewsocialtrends.org/factsheet/asian-americans-hmongin-the-u-s/

Polson M. 2018. Marketing marijuana: Prohibition, medicalization and the commodity. In Economy, Crime and Wrong in a Neoliberal Era. Carrier J (ed.). New York: Berghahn. p 140-71. Reinhart N, Barlett P. 1989. The persistence of family farms in United States agriculture. Sociol Ruralis 29(3/4):203-25.

Schneider J, Schneider P. 2008. The anthropology of crime and criminalization. Annu Rev Anthropol 37:351-73.
[SCSO] Siskiyou County Sheriff's Office. 2015. News Release: Siskiyou County Sheriff's Office Update on Marijuana Enforcement. Sept 25.

SCSO. 2016a. News Release: Sheriff's Office Outlines Plan to Attack Illegal Marijuana Grows in 2016. Mar 25.

SCSO. 2016b. News Release: Rising Crime Impacted by Lack of Jail Space, Illicit Drugs, and Other Factors Creating Major Public Safety Concerns. May 25.

SCSO. 2017a. Letter from Sheriff to Siskiyou County Board of Supervisors. June 15.

SCSO. 2017b. News Release: Sheriff's Office Illegal Marijuana \& Illicit Drug Update Search Warrants \& Drug Raids Target Illicit Drug Operations. Sept 29. SCSO. 2018. Sheriff Announces Hmong-American and Siskiyou County Town Hall. May 4. www.facebook. com/SiskiyouCountySheriff/ posts/2468992463126828

Shulman A. 2018. Is Siskiyou really ready for a change?': After lawsuit, Lopey starts Hmong town halls. Record Searchlight. May 18. www.redding.com/ story/news/local/2018/05/18/ siskiyou-really-ready-change-

lopey-starts-hmong-townhall/612858002/

Siskiyou County. 1996. Siskiyou County Comprehensive Land and Resource Management Plan.

Siskiyou County. 2005. Office of the County Administrator. Code of the West, the Realities of Rural Living: A Primer for Living in Siskiyou County California.

Siskiyou County. 2015. Board of Supervisors Minutes. March 10.
Siskiyou County. 2017a. Siskiyou County Planning Staff Report: Staff Report on Potential Commercial Medical Cannabis Cultivation Pilot Project. July 11.

Siskiyou County. 2017b. County of Siskiyou Board of Supervisors. Resolution Proclaiming a Local Emergency: Proliferation of Illegal Cannabis Cultivation. Sept 5. St. John P. 2017. Hmong pot growers in Siskiyou County seeking identity, profit - or both. LA Times. Sept 10. www. latimes.com/local/california/lame-hmong-marijuana-siskiyou20170910-htmlstory.html

Stoa R. 2018. Craft Weed: Family Farming and the Future of the Marijuana Industry. Cambridge: MIT Press.

Tarlock AD. 1999. Can cowboys become indians? Protecting western communities as endangered cultural remnants. Ariz State Law J 3:539-82.

US Census Bureau. 2017. QuickFacts Population Estimate for Siskiyou County, California July 1. www.census.gov/quickfacts/ fact/map/siskiyoucounty california/PST045217\#viewto

USDA NASS. 2017. California County Summary Highlights. p 251. www.nass.usda.gov/ Publications/AgCensus/2017/ Full_Report/Nolume_1, Chapter_2_County_Level/ California/st06_2_0001_0001. pdf

Walby K, Lippert R. 2012. Spatial regulation, dispersal, and the aesthetics of the city: Conservation officer policing of homeless people in Ottawa, Canada. Antipode 44(3):1015-33.

Walker P. 2003. Reconsidering 'regional' political ecologies: Toward a political ecology of the rural American West. Prog Hum Geog 27(1):7-24. 